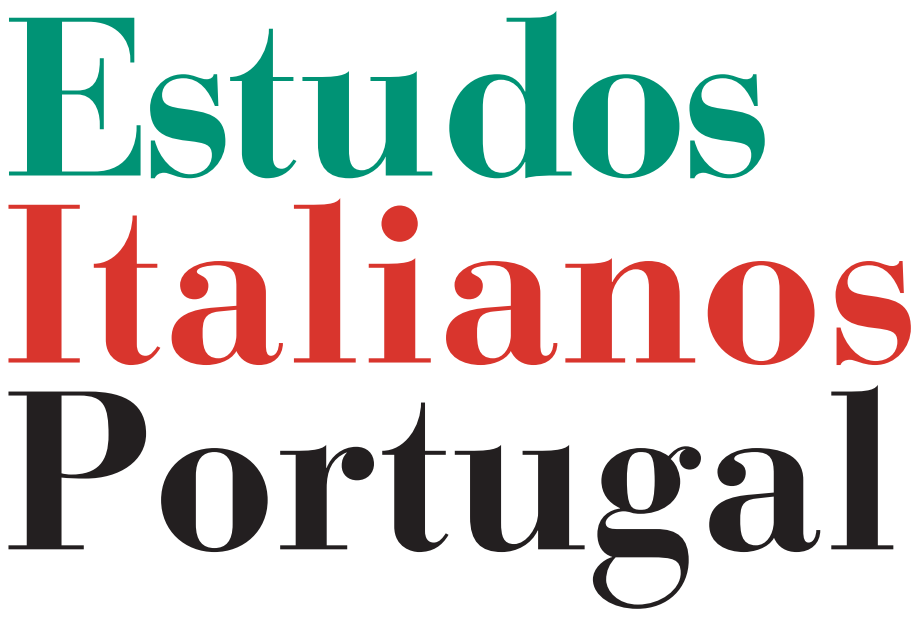

Instituto

Italiano

de Cultura

de Lisboa

Nova Série

$N^{0} 11$

2016 
Estudos Italianos em Portugal

Nova Série, N. ${ }^{\circ} 11,2016$

Instituto Italiano de Cultura de Lisboa

Direcção: Luisa Violo

Coordenação Editorial: Rita Marnoto

Conselho Científico: Aires A. Nascimento, Eugénio Lisboa, João Bigotte Chorão, Manuel G. Simões, Maria Manuela Tavares

Ribeiro

Conselho Editorial: Ernesto Rodrigues, Gianluca Miraglia, Isabel Almeida, Maria João Almeida

ISSN: 0870-8584

Depósito Legal: 228316/05

Design: FBA. Ferrand, Bicker \& Associados

Impressão e Acabamento: Simbolomania - Artes Gráficas, Lda.

Disponível na plataforma Impactum da Imprensa da Universidade de Coimbra:

https://digitalis.uc.pt/pt-pt/content/uc_impactum

Direcção e Administração:

Instituto Italiano de Cultura de Lisboa

Rua do Salitre, 146

1250-204 Lisboa

iiclisbona@esteri.it

www.iiclisbona.esteri.it

Coordenação:

Instituto de Estudos Italianos

Faculdade de Letras

Universidade de Coimbra

3004-530 Coimbra

rmarnoto@fl.uc.pt

Os trabalhos publicados são sujeitos a avaliação, de forma anónima, por especialistas internos e externos à Comissão Científica e à Comissão Redactorial da revista. 


\section{ÍNDICE}

Editorial

Dossiê - Sperduti nel buio: encontros e desencontros entre o cinema italiano e o cinema português

José-Augusto França, O cinema italiano e eu

Bruno Roberti, Sul cinema portoghese. Un viaggio sentimentale

Roberto Silvestri, Italia e Portogallo, rencontre unique

Simona Fina, Specchi di storia

Fausto Cruchinho, Roberto Rossellini humanista

Caterina Cucinotta, Un italiano tipicamente portoghese. Breve storia del cineasta Rino Lupo

Gian Luigi De Rosa, Alessandra Zuliani, O Quinto Império de Manoel de Oliveira tra humour eproblematiche linguistico-traduttive Marcello Sacco, Manoel, il regista, l'altro. Un ricordo teatrale del cineasta Manoel de Oliveira

Clelia Bettini, Buio in sala. Quasi dieci anni di cinema italiano in Portogallo con 8 1 1/2 Festa do cinema italiano

Artigos

Roberto Gigliucci, Versioni italiane di un'ottava dei Lusiadi dal XVII secolo ai nostri giorni

Rita Marnoto, Nuno Júdice, Caravaggio e o chiaroscuro - A conspiração de Cellamare 
Maurizio Bevilacqua, Il plurilinguismo nell'istruzione pubblica italiana: elementi di storia dell'insegnamento della lingua portoghese Gianluca Miraglia, I misteri di Yanez de Gomera

OBRA ABERTA

Umberto Eco, Obra aberta

RECENSŌES

Il Settecento e l'Ottocento in Portogallo; Il Novecento in Portogallo, a cura di Giulia Lanciani (Maria Luisa Cusati)

Con gran mare e fortuna. Circulação de mercadorias, pessoas e ideias entre Portugal e Itália na Época Moderna, org. Nunziatella Alessandrini, Susana Bastos Mateus, Mariagrazia Russo, Gaetano Sabatini (Vítor Serrão)

Gil Vicente, Auto da Barca do Inferno. La barca dell'Inferno, ed. Valeria Tocco et al. (Maria João Almeida, José Camões)

Eça de Queirós, Antero de Quental. Un genio che era un santo, trad. Mauro La Mancusa (Andrea Ragusa)

Veneza, versão de Antero de Quental, il. Harry Fenn, P. Skelton, Edward Whymper Senior, org. Andrea Ragusa (Manuel G. Simões)

Rita Marnoto, O petrarquismo português do "Cancioneiro geral" a Camões (Helder Macedo)

Editou-se... (Andrea Ragusa)

Paulo Cunha e Silva in memoriam (Rita Marnoto) 


\section{EDITORIALE}

Sono lieta di presentare, nell'ambito della nuova serie, l'undicesimo volume della Rivista Estudos Italianos em Portugal, dedicato al cinema.

Far conoscere il ricco patrimonio dell'arte cinematografica italiana e, allo stesso tempo, promuovere e sostenere la divulgazione delle sue produzioni filmiche più recenti è una delle attività che il nostro Istituto svolge con regolarità ed entusiasmo, incontrando il favore del pubblico sempre più attento alla presenza italiana.

Per questo motivo, sono certa che il dossier monografico approntato e dedicato proprio alla settima arte sarà accolto con grande curiosità e interesse. Gli articoli che lo compongono mettono in luce, da un lato, la presenza costante e massiccia dei film italiani in Portogallo durante un lungo periodo del ventesimo secolo e, dall'altro, il ruolo importante e spesso decisivo che la critica italiana ha svolto nella piena valorizzazione del cinema portoghese nel mondo.

Oltre al nutrito dossier, la rivista propone quattro articoli di vario argomento nei quali, fra l'altro, si discorre dei Lusiadi di Luís Vaz de Camóes, del Caravaggio e di Emilio Salgari, mentre la sezione 'Obra Aberta' ricorda la figura unica di Umberto Eco, scomparso nel mese di febbraio di quest'anno. Completano il volume, le recensioni accurate di opere rile- 
vanti per l'approfondimento delle relazioni culturali luso-italiane e un veloce aggiornamento dei titoli italiani pubblicati in traduzione portoghese.

Desidero, infine, ringraziare tutti coloro che hanno generosamente collaborato e contribuito alla realizzazione di questo volume e manifestare la doverosa riconoscenza alla Prof.ssa Rita Marnoto che, con la consueta professionalità e instancabile impegno, ne ha coordinato l'edizione.

Ringrazio la Prof.ssa Marnoto anche per l'omaggio in memoriam a Paulo Cunha e Silva, personaggio di spicco nel mondo culturale locale ed internazionale, prematuramente scomparso alla fine dell'anno 2015, che si è sempre prodigato per gettare ponti tra la nostra cultura e quella portoghese.

Luisa Violo 


\section{EDITORIAL}

Tenho o prazer de apresentar, no âmbito da nova série, o décimo primeiro volume da Revista Estudos Italianos em Portugal, dedicado ao cinema.

Dar a conhecer o rico património da arte cinematográfica italiana e, ao mesmo tempo, promover e suportar a divulgação da sua produção de filmes mais recentes é uma das atividades que o nosso Instituto desenvolve com regularidade e entusiasmo, indo ao encontro da preferência do público cada vez mais atento à presença italiana.

Por este motivo, estou convicta que o dossiê monográfico preparado e dedicado precisamente à sétima arte será acolhido com grande curiosidade e interesse. Os artigos que o compõem trazem à luz, por um lado, a presença constante e maciça dos filmes italianos em Portugal durante um longo período do século XX e, por outro, o importante papel frequentemente decisivo que a crítica italiana desenvolveu na divulgação plena do cinema português no mundo.

Para além do substancial dossiê, a revista propõe quatro artigos sobre assuntos vários nos quais, entre outros, se fala acerca dos Lusíadas de Luís Vaz de Camóes, de Caravaggio e de Emilio Salgari, enquanto a secção 'Obra Aberta' recorda a figura única de Umberto Eco, desaparecido em Fevereiro deste ano. Completam o volume as recensões cuidadas de 
obras relevantes para o aprofundamento das relaçóes culturais luso-italianas e uma veloz atualização dos títulos italianos publicados em português.

Desejo, por fim, agradecer a todos os que generosamente colaboraram e contribuíram para a realização deste volume e manifestar o devido reconhecimento à Prof. ${ }^{a}$ Rita Marnoto que, com o seu habitual profissionalismo e incansável empenho, coordenou a edição.

Agradeço também à Prof. ${ }^{a}$ Marnoto pela homenagem à memória de Paulo Cunha e Silva, personagem de relevo no mundo cultural local e internacional, prematuramente desaparecido no fim do ano 2015, sempre pródigo na criação de pontes entre a nossa cultura e a portuguesa.

Luisa Violo 


\title{
NUNO JÚDICE, CARAVAGGIO E O CHIAROSCURO - A CONSPIRAÇÃO DE CELLAMARE
}

\author{
Rita Marnoto*
}

\section{RETRATO}

Encosta-te à parede. A brancura

das pernas contra o negro da sombra. $\mathrm{O}$

risco da meia no risco do papel; e

os dedos que furam a pele. Os olhos fechados

no excesso da luz.

Nuno Júdice, Retrato (Regras da perspectiva $)^{1}$

EM MADDALENA IN ESTASI, uma das últimas obras de Caravaggio $^{2}$, o pintor leva o tenebrismo até ao seu cúmulo, ao dramatizar a tensão entre corpo luminoso e espaço indiscernível, entre visível e vazio, numa tela que penetra no objecto por enfatização de contornos. A palavra êxtase, que provém do

* Professora da Universidade de Coimbra, dedica-se ao estudo das relações literárias Portugal-Itália, com incidência sobre vários períodos e autores.

${ }^{1}$ Poesia reunida 1967-2000, pref. Teresa Almeida, Lisboa, D. Quixote, 2000, p. 389 (1. ${ }^{\text {a }}$ ed. de Regras da perspectiva, 1990).

${ }^{2}$ Michelangelo Merisi (1563-1610), que ficou conhecido por aquele que talvez seja o lugar de origem de seus pais. No seio de uma imensa bibliografia sobre a sua vida e obra, destacam-se: Giulio Carlo Argan, Storia dell'arte italiana, vol. 3, Firenze, Sansoni, 1975 [reed.], pp. 257-374; Helen Langdon, Caravaggio. A Life, Boulder, Westview, 2000; Ferdinando Bologna, "Merisi, Michelangelo", in Dizionario biografico degli italiani, vol. 73, Roma, Treccani, 2009, www.treccani.it/enciclopedia/ michelangelo-merisi_(Dizionario-Biografico)/ (consultado a 30-05-2016); Carlos Vidal, Deus e Caravaggio, Coimbra, Imprensa da Universidade de Coimbra, 2014, com bibliografia remissiva. 
grego e se difundiu através do latim tardio, significa de facto 'fora de si' (ex-stasis). Maria Madalena apreende-se quer na luz do seu corpo distendido, quer no negro da sombra que presentifica o transcendente. Os meios pictóricos utilizados estão para o momento de excepção que está a ser captado, levando ao seu extremo os princípios do Classicismo. Não existe um foco de luz exterior e o corpo fulgurante encontra-se geometricamente descentrado. A luminosidade fica contida dentro dos seus próprios limites, desenhados numa triangulação ascendente que parece desafiar as regras da perspectiva. A intensidade da luz e a intensidade da escuridão demarcam o êxtase, a brancura contra o negro da sombra, sem zonas de transição. A escuridão, que de modo algum tem a função de pano de fundo, é tão importante como as zonas de luz e ambas desenham as formas, fazendo valer o risco que marca o contorno.

Nas páginas iniciais de $A$ conspiração de Cellamare ${ }^{3}$, é assim que Nuno Júdice faz do arrojo de Caravaggio excesso:

O êxtase de Madalena é diferente do que também encontramos na Santa Teresa de Ávila de Bernini; mas a sensualidade que o pintor colocou na expressão do seu rosto reflecte um prazer a que ele acrescenta um ricto masculino. O ponto de partida é a mesma fusão erótica com o sagrado da santa mística de Bernini; mas o que a Madalena experimenta transforma-a numa figura andrógina a que as mãos juntas, com os dedos cruzados, dão um toque profano e quase herético na sua total entrega ao divino. Nuno Júdice, $A$ Conspiração de Cellamare, p. 15

O detalhe com que colhe, da fusão erótica com o sagrado, o traço andrógino que transforma o feminino, na plenitude de uma entrega tão intensa que toca o herético, é resultado de uma exasperação analítica que afinal desdobra a fortíssima tensão concentrada na tela. A plasticidade do

\footnotetext{
${ }^{3}$ Lisboa, D. Quixote, 2016.
} 


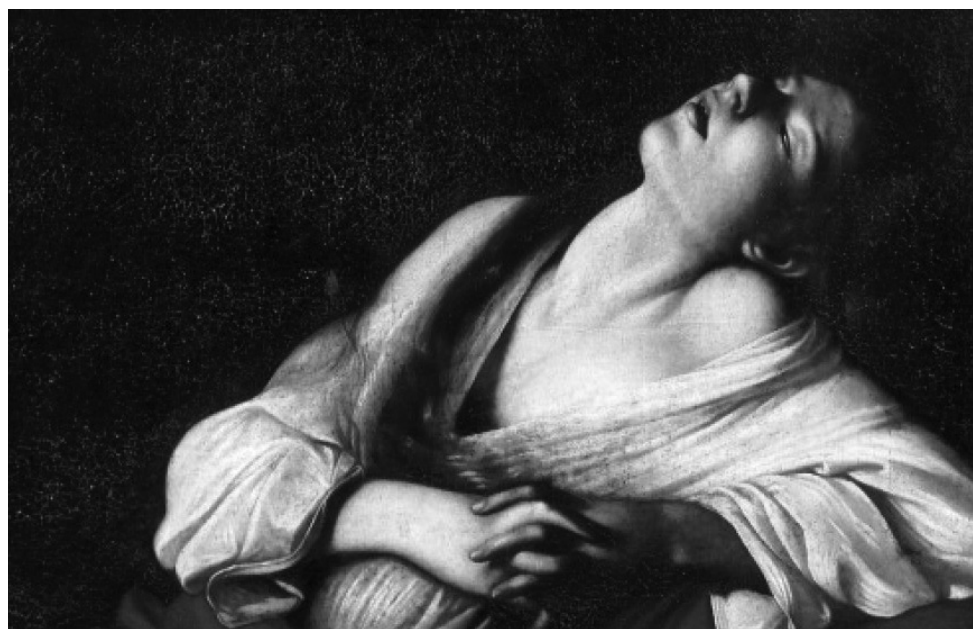

Michelangelo Merisi, "Il Caravaggio", Maddalena in estasi. Ólio sobre tela, (h) $91,5 x$ (l) 103,5cm. Colecção particular. www.repubblica.it/cultura/2014/10/24/ news/e_lei_la_vera_maddalena_svelato_il_mistero_di_caravaggio_98877106/ (consultado em 30-06-2016)

contorno é levada até às últimas consequências, forçando de tal maneira os seus limites que os destabiliza. Santa Maria Madalena é transportada do domínio do sagrado para o do profano, numa comparação com o conjunto escultórico de Santa Teresa de Ávila de Bernini que dialoga conceptualmente com uma obra esculpida cerca de meio século mais tarde.

A força do risco que inscreve o confim entre espaços descentrados, elevando a tensão ao seu cúmulo, é para Omar Calabrese um ponto essencial da ligação entre barroco e neobarroco ${ }^{4}$. O limiar é acentuado, em ambos os casos, pela exasperação do negro da sombra contra o excesso de luz, do instantâneo contra o metamórfico. O pintor leva o contorno ao seu cúmulo, vincando-o. $\mathrm{O}$ escritor supera o contorno, destabilizando-o.

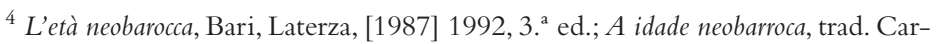
men de Carvalho, Lisboa, Edições 70, 1988. 
Caravaggio não se exercitou no desenho de pormenor. $\mathrm{O}$ estudo da materialidade dos seus quadros mostra a tenacidade com que assinalava os contornos. Para os delimitar, gravava a tela com objectos acutilantes.

Pelo seu lado, no plano da metaficção, as abundantíssimas considerações que ficam contidas em $A$ conspiração de Cellamare não deixam de traduzir o reconhecimento de um quadro sistémico de géneros literários:

O meu problema inicial era que eu não queria escrever um romance histórico; eu nem sequer queria escrever um romance. Seria uma mistura de géneros, entre o diário, as memórias e a ficção; mas já sabia, ao definir esta hibridez, que o resultado seria sempre classificado como não gozando de nenhum desses estatutos e, por isso, carecendo da solidez que se exige a um texto narrativo. Nuno Júdice, A conspiração de Cellamare, pp. 7-8

Contudo, esse reconhecimento, que deixa de fora uma poética da negatividade, não é mais do que ponto de partida para a superação de limites. Ao ser posto ao serviço da fusão entre componentes de ordem diversificada, acaba por acentuar a instabilidade dos confins que separam luz e sombra, não obstante a sua vincada inscrição conceptual. A instigar essa mutabilidade, o excesso de luz que incide sobre cada momento do contado, em clarôes metaficcionais e reverberações de ironia que continuamente metamorfoseiam o risco dos contornos, brancura e negro da sombra.

\section{A família Júdice}

[...] eu sabia apenas o que era referido na monografia de Estômbar do algarvio Ataíde de Oliveira, e se resumia a pouco mais que um parágrafo, com um ou outro erro, o que é compreensível porque, à data da publicação do livro, em 1911, não havia Internet 
como instrumento de trabalho, e as bibliotecas não dispunham de instrumentos necessários para um exacto estudo genealógico. Nuno Júdice, $A$ conspiração de Cellamare, p. 40

A Monografia de Estômbar. Concelho de Lagôa, de Francisco Xavier d'Athaíde Oliveira ${ }^{5}$, leva a cabo um estudo etnográfico da localidade desde o Paleolítico até à implantação da República. $\mathrm{O}$ que nas suas páginas se encontra contido é tudo quanto o escritor diz saber, inicialmente, acerca das origens italianas da sua família. Até que, por entre congeminações em torno de ficção e metaficção, de acesso à factualidade histórica e entrega à imaginação, acolhe o convite para uma viagem que o leva até um hotel no Sul de França, onde depois empreende indagaçõos acerca da sua ascendência italiana. Ou seja, coloca-se à partida num espaço descentrado, fora de Itália, a uma distância que requer e que se abre a todas as focagens de óptica a que irá proceder.

Athaíde Oliveira destaca vários membros da família, à qual reserva um parágrafo específico do capítulo "Familias illustres". Nele informa que o fundador do ramo genealógico português foi Paulo André Júdice ${ }^{6}$, o qual, no ano de 1707, abandonou a Itália por motivos políticos e se fixou em Portugal. A estirpe é apresentada desde as suas origens na Córsega do século XI, com os condes de Cinarca, até ao estabelecimento definitivo de alguns dos seus membros em Pisa e em Génova no século XVI. A partir daí, o etnógrafo chega a António Júdice e à conspiração de Cellamare:

Este Domingos Judice, entre outros, teve os dois filhos, Nicolau Judice, cardeal, e Antonio Judice, que promoveu em Paris uma conspi-

${ }^{5}$ Porto, Tipografia Universal, donde se cita. Sobre a família Júdice, pp. 187-192. Reed. Faro, Algarve em Foco Editora, 1987.

${ }^{6}$ Originariamente é precedido pela preposição del, del Giudice, a sigilar a pertença a uma estirpe. Athaíde Oliveira aportuguesa o nome para Judice/Júdice. Em $A$ conspiração de Cellamare escreve-se Giudice. 
ração conhecida por conspiração Cellamare, que vizava o poder do Regente, cuja regencia queria reivindicar para o rei de Hespanha. A conspiração foi descoberta, antes da sua execução.

Antonio Judice foi marechal de Campo e Embaixador de Hespanha em Paris: usava o titulo de principe de Cellamare e duque de Giovenazzo, e era tambem grande de Hespanha, Vice-Rei de Navarra e Cavalleiro do Espirito Santo. Nasceu em Napoles em 1657, e morreu em Sevilha a 16 de maio de 1733 sem filhos varões.

Esta informação poderá ser completada através da consulta das entradas "Cellamare, Antonio del Giudice, duca di Giovinazzo, principe di"8 e "Del Giudice, Francesco", do Dizionario biografico degli italiani, que fornecem dados históricos detalhados e bibliografia.

Segundo estas fontes, os del Giudice passaram de Génova a Nápoles no século XVI, para logo se integrarem no estrato dos baroni, através de um processo de ascensão típico do tecido social napolitano, decorrente da simbiose entre êxito de operações comerciais e apoio ao governo espanhol. Foi assim que Nicolò del Giudice (1587-1671) adquiriu os títulos de Príncipe de Cellamare em 1631 e de Duque de Giovinazzo em 1639. Ambos passaram para seu filho primogénito, Domenico (Nápoles, 1637-?), o tesoureiro do Reino de Nápoles, Embaixador de Espanha em França, Portugal e no Ducado de Sabóia, Vice-Rei de Aragão e membro do Conselho de Itália em Madrid, que era irmão do influente cardeal Francesco del Giudice. Her-

\footnotetext{
${ }^{7}$ Ib., p. 188. Transcrição sic.

${ }^{8}$ Informação sistemática, com ampla bibliografia, na entrada de Giuseppe Scichilone, in Dizionario biografico degli italiani, vol. 23, Roma, Treccani, 1979, www.treccani.it/enciclopedia/cellamare-antonio-del-Giudice-duca-di-Giovinazzo-principedi_(Dizionario-Biografico)/ (consultado a 30-05-2016).

${ }^{9}$ Informação sistemática, com ampla bibliografia, na entrada de Pietro Ottobòni, in Dizionario biografico degli italiani, vol. 36, Roma, Treccani, 1988, www.treccani.it/ enciclopedia/francesco-del-giudice_(Dizionario-Biografico)/ (consultado a 30-052016).
} 
dou-os, por sua vez, seu filho Antonio del Giudice (1657-1733). Homem de armas aguerrido e diplomata discreto, foi enviado como embaixador de Filipe $\mathrm{V}$ de Espanha a Paris, onde chegou em Maio de 1715, para defender os interesses espanhóis no xadrez dos tratados europeus, que tinham vindo a ignorar Filipe V, dando por descontada a assimilação de Espanha à França. Quando em Setembro Luís XIV deu o seu último suspiro, o futuro Luís XV tinha apenas quatro anos e o Duque de Orléans assumiu a regência. O Príncipe de Cellamare tornou-se então cúmplice da Duquesa de Maine, Luísa Benedita de Bourbon, desejosa de fazer valer a condição de seu marido, filho legitimado de Luís XIV e da Marquesa de Montespan. A conjura desabou como um castelo de cartas.

Esta informação está disponível na internet, a tal "que não havia" no tempo de Athaíde de Oliveira (p. 40). Além disso, Alfred Baudrillart dedicou à história das relações entre Espanha e França, durante este período, os volumes de Philippe $V$ et la cour de France (1890), observando, a esse propósito, que seria mais exacto designar a conjura como conspiração da Duquesa de Maine do que como conspiração de Cellamare. Acrescente-se que o próprio Príncipe deixou um manuscrito com as suas memórias.

Contudo, e apesar de ter sido escolhida uma imagem da Duquesa de Maine para capa de A conspiração de Cellamare, o escritor faz jus ao seu antepassado Antonio del Giudice, numa alternância entre protagonismos. O que acrescenta à monografia de Athaíde Oliveira, como fonte de informação acerca da conspiração de Cellamare, não são primordialmente fontes historiográficas, mas um clássico da literatura romanesca que deliciou os leitores do século XIX. Com efeito, é esse mesmo livro que leva na sua bagagem até ao Sul de França: Le Chevalier d'Harmental (1842), de Alexandre Dumas. Diz servir-se, além disso, da narrativa de Jean Va- 
tout, La conspiration de Cellamare (1832), e dos breves mas expressivos acenos de Marguerite Jeanne Cordier de Staal Delaunay, aia da Duquesa de Maine, nos seus Mémoires (1. ${ }^{\mathrm{a}}$ ed. 1755$)^{10}$. Se pelo menos parte do romance de Dumas terá sido escrita por Auguste Maquet, Vatout será a bom título um cronista com mais imaginação do que Dumas e Maquet juntos. $\mathrm{O}$ manejo perspéctico da história é uma estratégia colocada ao serviço da instabilidade das fronteiras que a separam da ficção.

É assim que o enredo se vai adensando, à medida que a atenção do escritor se concentra na noite que Luísa Benedita teria passado com o Príncipe de Cellamare, antes de este ter recebido o Ordre de la Mouche à Miel. Essa noite passa pois a converter-se no grande motivo de indagação:

No entanto, perguntará o leitor, porque estava eu a ler esse romance? A resposta é tão simples como isto: porque é nele que Alexandre Dumas conta em pormenor a conspiração de Cellamare e descreve, com uma exactidão de historiador atento a cada pormenor da História, a entronização de Antonio Giudice na Ordem da Mosca do Mel, a que ele acedeu depois de passar a noite no barco com a duquesa de Maine, Luísa Benedita.

Nuno Júdice, A conspiração de Cellamare, p. 31

É no XXV capítulo de Le Chevalier d'Harmental que é detalhadamente descrito o cerimonial de imposição dessa ordem ao Príncipe de Cellamare, na corte do Palácio de Sceaux, pelas quatro da tarde. A noite no barco que o escritor diz ter precedido a atribuição do grau perde-se no escuro da sombra, entre fantasias de fusão erótica.

Ao aplicar princípios dedutivos e indiciais a um espaço de ficção literária, para apurar a sua ascendência italiana, o

${ }^{10}$ Ver A conspiração de Cellamare, pp. 30-31, 62, 74-75. 
escritor não pode deixar de votar a indagação ao fracasso. Entretanto, o objectivo primeiro de apurar as origens italianas da família Júdice, ao derivar para outros interesses, ao sabor de ficçōes, de ficções de ficções, memórias e gostos pessoais, confere a $A$ conspiração de Cellamare a atractividade lúdica de uma tela de jogos de sombras que constantemente se fazem e desfazem.

O leitor já tinha sido avisado que não esperasse do livro a "solidez que se exige a um texto narrativo" (p. 8).

\section{Geografia do CaOS}

[...] Hesito entre

a luz e a obscuridade, sabendo que é nessa fronteira

que poderá surgir um brilho breve como a interrogação suspensa dos seus lábios: o tempo? A paisagem?

As casas? Responder-lhes-ia: só o dia e a noite prosseguem

o seu curso, num céu indiferente ao que se passa

na terra. $[\ldots]$

Nuno Júdice, Geografia do caos $^{11}$

Começando pelas casas e pelo Palácio que hoje se continua a chamar de Cellamare, é a Antonio del Giudice que a mansão deve tanta da sua grandeza ${ }^{12}$. Fora mandado construir em inícios do século XVI pelo abade Giovanni Francesco Carafa, do ramo dos Príncipes Stigliano, como casa de campo, naquela que então era uma zona periférica de Nápoles, Chiaia, sendo depois aprimorado pelo arquitecto Ferdinando Manilo. Em 1647 foi tomado pelos revoltosos de Masaniello e a

\footnotetext{
${ }^{11}$ Lisboa, Assírio e Alvim, 2005, p. 9.

${ }^{12}$ No seio de uma abundante bibliografia, ver Silvana Savarese, Palazzo Cellamare. La stratificazione di una dimora aristocratica (1540-1730), Napoli, Edizioni Scientifiche Italiane, 1996; Massimo Pisani Massamormile, Il Palazzo Cellamare. Cinque secoli di civiltà napoletana, Napoli, Electa, 2003.
} 
seguir usado pelos monges de Santa Úrsula como leprosaria, até que é adquirido pelos del Giudice. Algo parecia vinculá-lo ao mundo das artes para todo o sempre. Mais entendido no campo da arte do que em conspirações, Antonio del Giudice encarregou do seu restauro nada mais nada menos do que Ferdinando Fuga, o arquitecto que trabalhou com Vanvitelli em Caserta. Herdado pela filha, Costanza, casada com Francesco Caracciolo, o Palácio permaneceu ligado à aura de outra família ligada às letras. Foi depois alugado ao Príncipe de Francavilla, Michele IV Imperiali, que chamou, também ele, destacados artistas para restruturarem espaços que abrilhantou com festas e ricevimenti, dele fazendo, nas palavras de Benedetto Croce, "come il centro dell'alta Società napoletana"13. Hospedou forasteiros do coturno de Giacomo Casanova, Goethe, Angelica Kauffmann ou Jacob Philipp Hackert ${ }^{14}$.

Contudo, o hóspede do Palácio mais decisivamente envolvido em A conspiração de Cellamare é Caravaggio. Aí passou a derradeira estação de uma existência de desassossego, quando se encontrava ao serviço de Costanza Colonna, tia daquele que então era seu proprietário, Luigi Carafa Colonna. Costanza, viúva do Marquês de Caravaggio, Francesco Sforza, falecido em 1580, era uma mulher de ideias avançadas. $\mathrm{O}$ autor de $A$ conspiração de Cellamare parece colher essa faceta, num jogo de tempos, ao fazer de Maddalena in estasi, pintada num período que pode ir de finais de 1609 à primeira metade do ano seguinte, um retrato de Costanza Colonna encomendado pelo seu próprio marido

${ }^{13}$ Benedetto Croce, Aneddoti di varia letteratura, Napoli, R. Ricciardi, 1942, vol. 2, p. 262.

${ }^{14}$ Já no século XX, terminada a segunda guerra, o espectáculo continuou. Foi construído na sua cave, escavada no tufo vulcânico, aquele que é o maior cinema de Nápoles, com cerca de 3000 lugares, sob projecto de uma das poucas mulheres que em Itália participou no movimento da arquitectura moderna, Stefania Filo Speziale. 
(pp. 48, 137) ${ }^{15}$. Certo é que a tela atraiu de tal maneira o interesse dos caravaggeschi que as hibridações de falsos e reproduções prosperaram. Foram, até há bem pouco tempo, o guião da odisseia de críticos e historiadores da arte em busca do original perdido.

Em 1606 Caravaggio vira-se forçado a abandonar Roma por ter cometido um assassínio. Partiu para Malta, passou à Sicília e no Outono de 1609 seguiu daí para Nápoles, assinalando todo esse mapa com uma fieira de obras de tema religioso que traduz bem o seu anseio de obter remissão. Contava com a protecção da potentíssima família Colonna e de alguns prelados romanos, com relevo para o cardeal Scipione Borghese, coleccionador distinto.

$\mathrm{Na}$ barcaça em que descreveu a sua última viagem, de Nápoles para Porto Ercole, levava consigo três telas de feitura recente, duas com São João e uma com Santa Maria Madalena. Morreu de febres a 18 de Julho de 1610, sem nunca ter alcançado Roma, e a embarcação regressou à origem com as pinturas que foram entregues, na última morada napolitana de Caravaggio, à marquesa Costanza Sforza Colonna. Uma delas veio a chegar às mãos do cardeal Borghese, tudo levando a crer que seja o S. Giovanni que actualmente se encontra na Galeria Borghese. De um

\footnotetext{
${ }^{15}$ Victoria Turvey Sauron ("Mirror", in Conceptual Odysseys. Passages to Cultural Analyses, ed. Griselda Pollock, London, I. B. Tauris \& Co. Ltd, 2007, pp. 36-50) traçou a história da representação iconográfica de Santa Maria Madalena, descrevendo o itinerário histórico através do qual a imagem da mulher degradada vai deixando emergir a delicadeza da sua humanidade. Acrescente-se um ponto de viragem decisivo dessa evolução, o poema latino de Petrarca Dulcis amica Dei, dedicado à santa que segundo a tradição se isolou em Sainte Baume, na Provença, para se votar à penitência. Apesar de nada haver, no texto da Bíblia, que ponha em causa Maria Madalena, a proximidade de uma mulher com Cristo e os Apóstolos susceptibilizou os exegetas. A remoção do estigma transformou-se em rico manancial da ficção pósmoderna. Dan Brown explora a sua presença ao lado de Jesus Cristo na Ultima cena, de Leonardo, e Elizabeth Cunningham associa-a a um divino feminino e feminista na série de quatro livros que editou de 2006 a 2011.
} 
segundo São João e de Santa Maria Madalena perdeu-se entretanto o rastro.

Sabia-se que a tela tinha permanecido em Nápoles, onde em 1612 o pintor flamengo Louis Finson dela fez uma das mais conceituadas cópias, hoje pertencente ao Musée des Beaux-Arts de Marselha. Contudo, foi apenas em Março de 2016 que o original da Maddalena in estasi se deu a conhecer ao público, no Museu de Arte Ocidental de Tóquio. De Nápoles, devia ter passado a Roma por finais do século XVII. $\mathrm{O}$ seu paradeiro ficou porém em suspenso, até que muito recentemente reapareceu em posse de uma família que há várias gerações a detinha, sem nunca a ter identificado como obra-prima de Caravaggio ${ }^{16}$.

Uma viagem até Tóquio para admirar o original da tela é a única possibilidade de a redimir da obscuridade dos séculos. A lonjura do espaço e do tempo a percorrer, comparados com o brilho de um instante na contemplação de Maddalena in estasi, levam porém o escritor a hesitar, pois bastará um catálogo com uma boa reprodução (p. 48). O original não se confunde com a cópia, mas um e outro desdobram-se em luzes e sombras que mostram ao leitor que não lhe resta mais do que deixar-se seduzir pelo ludismo da ficção. É nessa fronteira que radica o brilho breve de cada interrogação.

\section{GeOMETria VARiáVEL}

[...] e

então, como se fosse um outro princípio, os pedaços

da alma juntam-se, enchem todo o espaço da sombra, e logo se dissipam, como névoa, quando o último

${ }^{16}$ A autenticidade da tela foi assegurada por Mina Gregori, a especialista de Caravaggio que se formou com Roberto Longhi. Ver "È lei la vera Maddalena. Svelato il mistero di Caravaggio", La Reppublica, 24-10-2014. Apesar de os seus actuais proprietários terem decidido preservar o anonimato, disponibilizaram-na para a exposição japonesa. 
sol desaparece no horizonte, como o deus que john donne viu morrer, ao caminhar para oeste, levando atrás de si, num peso de esfera, a sua própria alma. Nuno Júdice, Sphera Mundi (Geometria variável) ${ }^{17}$

Maddalena in estasi é o princípio da cadeia de anamorfoses que percorre $A$ conspiração de Cellamare, ganhando particular destaque no caso das personagens femininas, em instantes de aparição dotados de uma fortíssima e sedutora visualidade.

Quando a personagem da Açafata entra em cena, o escritor passa a desenhar, sem mais, "o recorte do queixo, dos lábios, do nariz, tudo apresentado com a perfeição necessária para que o leitor se sinta à vontade para imaginar a beleza da Açafata no momento em que a transformo em personagem" (pp. 35-36). O resto é entregue aos olhos de quem lê. Está em causa o mesmo propósito de escapar ao tédio do realismo que faz com que não a designe pelo seu próprio nome. É certo que enquadramentos fugazes mostram pedaços soltos desta personagem e da mulher que acompanha o "homem da sombra": "camisa branca", "cabelos de um castanho dourado" (p. 35), "lábios que não precisavam de qualquer pintura de bâton para ressaltarem na brancura do rosto" (p. 47), ou uma figura perfeitamente bronzeada que a luz mostra quando "se reclina num sofá de veludo vermelho" (p. 45). Da junção destes pedaços resulta uma espécie de patch work da tela de Caravaggio, formado por instantes de fulgor.

Personagens femininas em metamorfose entram e saem de cena a todo o momento. Logo nas primeiras páginas, como acima se disse, é Costanza Colonna que penetra na tela para personificar Maddalena in estasi. Desta Costanza, Marquesa de Caravaggio, decorre uma outra Costanza, a filha de Antonio del Giudice que assim teria sido chamada, cerca de um século depois, em homenagem à comitente do pintor (pp. 15-16). Num nível mimético inferior que força a mise

\footnotetext{
${ }^{17}$ Lisboa, D. Quixote, 2007, 2. ${ }^{a}$ ed., p. 45 (1. ${ }^{a}$ ed. 2005).
} 
en abyme, são colocados os corpos das mulheres que andam pelas ruas estreitas de Nápoles e que Goethe teria procurado se tivesse visto a Maria Madalena de Caravaggio (pp. 67-68). Neste caso, a um Goethe que discorre com Angelika Kauffmann sobre o uso das cores na pintura, o escritor sobrepõe um outro, que procura o ocre argiloso da tela num corpo menos efémero (pp. 67-68).

Este desdobramento de identidades femininas adquire porém particular densidade no caso da personagem designada como Açafata. O nome que o escritor lhe dá adequa-se bem à sua função de pivot dos contactos que estabelece, a partir do hotel em que se encontra instalado no Sul de França, a fim de indagar as suas origens italianas. Contudo, leva também a marca de Sade e do seu cardápio de aias. Sade e Caravaggio são duas figuras em constante junção e dissipação. Se o quarto de hotel que foi atribuído ao escritor é dedicado a Sade, a irreverência do sedutor moralista é um ingrediente ficcional tão instigante que o aloja também no Palácio de Cellamare (p. 18). Justifica a sua presença com uma outra conspiração de sombra: como o escritor francês chegara a Nápoles na condição de fugitivo, não podia registar o seu nome no livro de hóspedes.

A Açafata é o medium que instiga a sedução pela transmutação de luz e sombra. Depois de contar que tem sonhos inenarráveis que a deixam num estado de transição entre o sono e a vigília, que faz um doutoramento sobre pensamento místico e descrê no racionalismo, apesar de ser agnóstica (p. 54), logo o escritor nela revê mais uma Costanza Colonna (pp. 46-48). Desta feita, a representação de Maria Madalena continua a ser motivo propulsor. Daqui, a Açafata passa então a possível modelo de uma Maddalena penitente que decora o Palácio Dória em Roma e que o escritor decide atribuir a de Jacob von Loo (p. 56). Tem um efeito tal sobre ele que o põe fora de si, deixando-o mergulhado, a ele próprio, num estado extremo de obsessão e confusão (p. 58). 
É então que a transforma numa outra aia, a expedita dama da Duquesa de Maine, Marguerite-Jeanne Cordier Staal de Launay, ao que se segue uma nova transmutação em sósia da própria Duquesa. O ponto alto da captação do instante ocorre porém durante a visita à igreja, quando a fotografia da Açafata que tira em contraluz lhe revela o halo da Santa do Palácio Dória, Maddalena penitente. De tão excessivo, o jogo entre luz e sombra acaba por dissipar o seu corpo na transparência (pp. 80-82).

Se o excesso de luz ofusca os corpos, a sombra densifica-se. Há uma personagem que detém toda a informação acerca das origens italianas da família del Giudice, o especialista de história napolitana designado como homem da sombra. As poucas palavras que diz apagam-se porém na escuridão que o envolve. É tão impenetrável que o escritor opta por o fazer desaparecer da esfera da escrita (pp. 44-45).

"Margarite-Jeanne olhava-me agora como se eu fosse um deus" (p. 87), anota, desdobrando mais uma vez o encontro no Sepulcro entre Maria Madalena e o Deus que viu morrer (Jo. 20.11). Apesar de ter cancelado o homem da sombra, a sua figura continua a agitar o vazio, na vertigem da mão "que parecia de mármore" (p. 60), pronta a levar quem a toca atrás de si, pelos abismos do olhar, até ao ponto de fuga que o escritor desenhou num peso de esfera.

Está o livro prestes a terminar, e ainda se interroga sobre quem teria sido o modelo da Maddalena penitente de Jacob van Loo (p. 137). O leitor bem teria notado que a Maddalena penitente do Palácio Dória não é, ao contrário do que o escritor diz, de Jacob von Loo, mas de Caravaggio:

[Em Roma] entrei praticamente em todas as igrejas e museus por onde ia passando. Constatei, baseado nessa experiência devastadora, que, depois de admirarmos meia dúzia, já não é possível distinguir o que é real e o que é trompe l'oeil.

Nuno Júdice, A conspiração de Cellamare, p. 136 


\section{Metafísica cosmológica}

[...] As constelações, que eu acompanhava num mapa onde os nomes vinham indicados em latim, reduziam a uma escala humana aquilo que, para além do olhar, entrava numa dimensão divina.

Nuno Júdice, Metafísica cosmológica (O estado dos campos) ${ }^{18}$

Se a relação entre pintura e literatura contém em si uma geometria de variaçóes que, ao despoletar a visualidade da escrita, se desdobra numa cadeia de anamorfoses, a Maddalena in estasi de Caravaggio é o fulcro dos deslocamentos lúdicos que instigam o jogo entre verdadeiro e falso, história e ficção, luz e sombra. Culmina no mapa cuja legenda, escrita numa outra língua, só a ficção pode dizer.

$\mathrm{Na}$ sombra de $A$ conspiração de Cellamare alojam-se, tal como na tela de Caravaggio, as constelações de um poder que tudo vê e tudo sabe. Contudo, sombras, anseios e saltos de coerência reduzem a tela de Caravaggio à sua escala humana. Desfez-se o vazio da escuridão em que um corpo fulgurante, fora de si, encontrava o absoluto desenhado pelo contorno da tela. O desdobramento das formas, a metamorfose e a dúvida fazem parte de uma constelação terrena.

Quando no dia 18 de Julho Caravaggio, pouco depois de ter aportado a Porto Ercole, entrou na dimensão que o levou finalmente para fora de si, deixou a sua Maddalena in estasi definitivamente entregue à escala humana do chiaroscuro.

${ }^{18}$ Lisboa, D. Quixote, 2003, p. 108 
